\title{
STUDY ON REDUCTION KINETICS OF IRON ORE SINTER USING COKE DUST
}

\author{
ARGHYA MAJUMDER ${ }^{1}$, BITAN KUMAR SARKAR ${ }^{2}$, MAHARSHI GHOSH DASTIDAR ${ }^{3}$ \\ GOPES CHANDRA DAS ${ }^{4} \&$ RAJIB DEY ${ }^{5}$ \\ ${ }^{l}$ QA\&TD, Rashtriya Ispat Nigam Ltd (RINL), Visakhapatnam, India \\ 2,3,4,5 Department of Metallurgical and Material Engineering, Jadavpur University, Kolkata, India
}

\begin{abstract}
Sintering is the most important process where iron ore fines are converted into a suitable lumpy product for blast furnace consumption. In this study, received sinter from Vizag Steel Plant, India has been used. The solid state isothermal reduction kinetics has been carried out using coke dust (treated as industrial waste) as reductant at temperature $1373 \mathrm{~K}$ over a period of time from 5 to 90 minutes. The chemical analyses have been performed to get the degree of metallization of the reduced sinters and these data are used as input for the determination of the best fitted kinetic model. The characterizations of the reduced sinters are analyzed by XRD. The reduction mechanism is found to be contracting geometry.
\end{abstract}

KEYWORDS: Sinter, Coke Dust, Isothermal Kinetic Study, Reduction \& Degree of Metallization

Received: Jan 02, 2018; Accepted: Jan 23, 2018; Published: Feb 07, 2018; Paper Id.: IJMMSEFEB20183

\section{INTRODUCTION}

Sinter is one of the prime feed materials for the conventional Blast Furnace Iron making process. Sintering process involves agglomeration of iron ore fines (typical size range in between $9 \mathrm{~mm}$ to $0.15 \mathrm{~mm}$ ) into a porous mass by incipient fusion caused by combustion within the mass of the ore particles. To obtain the necessary size or load-bearing strength of the final sinter, a certain level of material coalescence is required. Melt volume (affected by the ore properties-composition, porosity and size) and flowability of the molten system at flame front are the key factors to get better efficiency of the sintering process [1-4]. Liu et al [5] have reported the effect of ore type on densification in liquid phase sintering regime, in order of porous $>$ dense $>$ regent as the porous ore take in more readily to form a more deformable system. The formation of more melt in the lower bed improves the ability of the system to coalesce. A wide variety of final sinter is observed, which solely depends on the chemical composition of raw materials taken. These sinters are mainly multiphase materials having heterogeneous microstructure. Hence, proper selection of process and operation variables are generally important in order to achieve better quality of sinter as well as greater productivity [6]. The main mineral phases observed in the finals sinter are hematite, magnetite, silico-ferrites of calcium and aluminium (SFCA) and silicates. To get the high quality sinter product, the SFCA is the desirable phase. The formation of SFCA on the phase composition of sinter is mainly influenced by the effect of sintering temperature, $\mathrm{CaO} / \mathrm{SiO}_{2}$ ratio, sintering gas atmosphere and cooling procedure [7]. High temperature $\left(1250-1300^{\circ} \mathrm{C}\right)$ mainly favors the formation of SFCA [8]. But due to a further increase in temperature, the SFCA decomposes as raising the temperature promotes the reduction of $\mathrm{Fe}^{3+}$ in the SFCA crystal structure to $\mathrm{Fe}^{2+}$. Increasing $\mathrm{CaO} / \mathrm{SiO}_{2}$ ratio and oxygen partial pressure have positive impact in favour of the formation of SFCA phase [9-13]. Andrews et al [14] have carried out laboratory-scale experiments 
using coal ash fusion furnace to study the effects of melt formation on the analogue sinter mix tablet reshaping at sintering temperatures. Loo and Heikkinen [15] have investigated the sinter properties at different spots within a sinter bed and reported that increasing sinter temperatures produce denser sinter particles. The mineralogical and morphological characteristics of sinter are heavily influenced by changing the basicity of sinter resulting different values of the reduction, degradation index (RDI) and reducibility index (RI) [16,17].

Solid state reduction kinetics is very important to study by which one can depict a particular reaction type and its rate equation by translating it mathematically [18-22]. P. Kowitwarangkul et al [23] have studied the kinetic models of reduction of self-reducing pellets (SRP) at isothermal and non-isothermal condition and estimated the value of corresponding activation energy. The self-reducing pellets (SRP) consist of iron ore fines and solid carbonaceous reducing agents like coal, coke and charcoal. Sarkar et al [24] have studied the kinetics of reduction for magnetite ore with high titanium content using lean grade coal and also evaluated the corresponding activation energies. They have reported that the kinetic mechanism follows mixed model type where contracting geometry (CG3; activation energy $93.42 \mathrm{KJ} / \mathrm{mol}$ ) is found to be the initial mechanism followed by diffusion controlled mechanism (Jander kinetic model; D4; activation energy $179.80 \mathrm{KJ} / \mathrm{mol}$ ) in the later part of the reaction. Similar type of mixed model mechanism (initial stage is controlled by gaseous diffusion mechanism and final stage is controlled by both gaseous-diffusion and chemical reaction) has also been observed during the reduction kinetics of iron ore-coal composite pellets under non-isothermal condition in inert atmosphere [25]. Another work has also been reported on the kinetics of the smelting reduction of iron ore by a graphite crucible and carbon-saturated molten iron between $1400^{\circ} \mathrm{C}$ and $1550^{\circ} \mathrm{C}$ which is continuously observed in situ by X-ray fluoroscopy. The activation energies for the reduction by the graphite crucible and the molten iron were 24.1 and 22.9 $\mathrm{kcal} / \mathrm{mol}$, respectively [26].

In the present investigation, solid state reduction of iron ore (hematite) sinter (received from Rashtriya Ispat Nigam Ltd. (RINL), India) using coke dust has been carried out. Coke dust is treated as an industrial waste which is used here as a reductant. Isothermal reduction kinetics has been studied to evaluate the exact kinetic mechanism during solid state reduction of sinter. The characterization of phase analysis is observed using XRD. Chemical analysis of the reduced sinter has also been done for the determination of the degree of metallization.

\section{EXPERIMENTAL}

\section{Characterization of Sinter}

Hematite ore (below $6 \mathrm{~mm}$ size) is used for sinter making. Sinter has been collected from Sinter Plant, Rashtriya Ispat Nigam Ltd. (RINL), Visakhapatnam, India. The composition of sinter is analyzed by using x-ray Flouroscence (WDXRF, PanAlytical) and shown in Table 1.

Table 1: WDXRF Analysis of Iron Ore Sinter

\begin{tabular}{|l|c|c|c|c|c|c|c|c|c|l|}
\hline Element/Compound & $\mathrm{Fe}(\mathrm{T})$ & $\mathrm{FeO}$ & $\mathrm{CaO}$ & $\mathrm{SiO}_{2}$ & $\mathrm{Al}_{2} \mathrm{O}_{3}$ & $\mathrm{MnO}$ & $\mathbf{M g O}$ & $\mathrm{P}_{2} \mathbf{O}_{5}$ & $\mathrm{TiO}_{2}$ & $\mathrm{CaO} / \mathrm{SiO}_{2}$ \\
\hline Concentration & 57.69 & 7.87 & 9.12 & 5.73 & 1.31 & 0.11 & 1.63 & 0.05 & 0.10 & 1.59 \\
\hline
\end{tabular}




\section{Analysis of Coke Dust}

Coke dust collected from the coke oven by product plant (COBP) of the Rashtriya Ispat Nigam Ltd. (RINL), Visakhapatnam, India has been used as reductant for the present experiments. Standard proximate as well as ultimate analyses (LecoTruSpec) are carried out for the determination of composition of coke dust and are tabulated in Table 2.

Table 2: Proximate and Ultimate Analysis of Coke Dust

\begin{tabular}{|c|c|c|c|c|c|c|c|}
\hline & \multicolumn{4}{|c|}{ Proximate Analysis } & \multicolumn{3}{c|}{ Ultimate Analysis } \\
\cline { 2 - 7 } & $\begin{array}{c}\text { Fixed } \\
\text { carbon } \\
(\%)\end{array}$ & $\begin{array}{c}\text { Volatile } \\
\text { matter }(\%)\end{array}$ & $\begin{array}{c}\text { Moisture } \\
(\%)\end{array}$ & $\begin{array}{c}\text { Ash } \\
(\%)\end{array}$ & $\begin{array}{c}\text { Carbon } \\
(\%)\end{array}$ & $\begin{array}{c}\text { Hydrogen } \\
(\%)\end{array}$ & $\begin{array}{c}\text { Nitrogen } \\
(\%)\end{array}$ \\
\hline $\begin{array}{c}\text { Coke } \\
\text { dust }\end{array}$ & 79.46 & 4.01 & 0.53 & 16 & 87.5 & 0.065 & 1.351 \\
\hline
\end{tabular}

Thermo gravimetric-differential thermal analysis (TG/DTA; Perkin Elmer) of coke dust has been carried out under nitrogen atmosphere (UHP Grade $99.99 \% \mathrm{~N}_{2}$ ) from room temperature to $1273 \mathrm{~K}$ (Ref. Figure 1). The weight loss is minimum upto $873 \mathrm{~K}$ which corroborates the presence of low moisture and volatile matter content in coke dust. A gradual weight loss after $873 \mathrm{~K}$ can be explained by the fact that the apparent pores of the fine coke dust are filled with air and secondly the nitrogen used is not fully free from oxygen. Therefore, oxygen from both the sources would be responsible for burning of coke dust at high temperature showing the exothermic peak in the DTA analysis at around 923K-1123K.

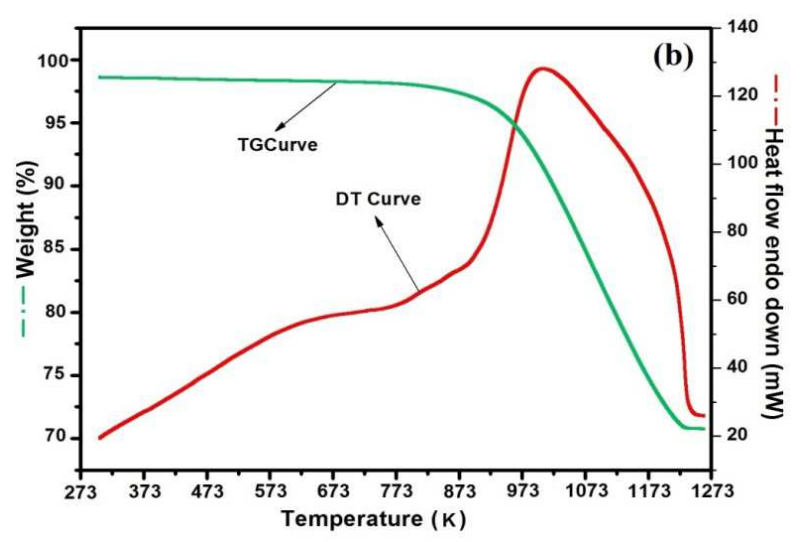

\section{Experimental Procedure}

Figure 1: TG/DT Analysis of Coke Dust

The reduction experiments have been carried out in a PID controlled electrically heated tubular furnace having temperature accuracy of $\sim 5^{0} \mathrm{C}$. Stoichiometrically for reduction of $10 \mathrm{gm}$ sinter, $2.26 \mathrm{gm}$ coke dust has been used. In each experiment, the exact weight of sinter and coke dust as stated earlier is measured using an electronic balance (WENSAR, Model No: PGB1000 with accuracy 0.001) and is introduced in an Inconel cylinder with an exhaust tube. After the furnace ramp up to the experimental temperature, the inconel cylinder is inserted into the hot zone of the furnace and kept for a specified time length isothermally. During this isothermal holding the reduction reaction occurs that results the emission of the product gases through the tubular outlet. After certain reduction time, the outlet of the tube is sealed. Thereafter, the sealed inconel cylinder is taken out and allowed to cool. After room temperature is reached, the reduced sinter is removed from the inconel cylinder and weighed in the electronic balance. 


\section{Isothermal Reduction Kinetic Study of Iron Ore Sinter}

The direct reduction experiments of iron ore sinter are carried out isothermally in a standard closed reactor at temperature $1373 \mathrm{~K}$ for a period of 5 to 90 minutes. The conventional gas-solid reaction mechanisms for isothermal kinetic study are mentioned hereunder.

$$
\begin{aligned}
& \alpha^{2}=\mathrm{kt} \\
& {[\alpha+(1-\alpha) \ln (1-\alpha)]=\mathrm{kt}} \\
& {\left[1-2 / 3 \alpha-(1-\alpha)^{2 / 3}\right]=\mathrm{kt}} \\
& {\left[1-(1-\alpha)^{1 / 3}\right]^{2}=\mathrm{kt}} \\
& {\left[(1+\alpha)^{1 / 3}-1\right]^{2}=\mathrm{kt}} \\
& {\left[(1-\alpha)^{-1 / 3}-1\right]^{2}=\mathrm{kt}} \\
& \alpha=\mathrm{kt} \\
& {\left[1-(1-\alpha)^{1 / 2}\right]=\mathrm{kt}} \\
& {\left[1-(1-\alpha)^{1 / 3}\right]=\mathrm{kt}} \\
& {[-\ln (1-\alpha)]=\mathrm{kt}} \\
& {\left[(1-\alpha)^{-1 / 2}-1\right]=\mathrm{kt}} \\
& {\left[(1-\alpha)^{-1}-1\right]=\mathrm{kt}}
\end{aligned}
$$$$
\text { Parabolic }\left(\mathrm{D}_{1}\right)
$$$$
\text { Valensi Barrer }\left(\mathrm{D}_{2}\right)
$$$$
\text { Ginstling Brounsthein }\left(\mathrm{D}_{3}\right)
$$$$
\text { Jander }\left(\mathrm{D}_{4}\right)
$$

Anti Jander $\left(\mathrm{D}_{5}\right)$

Zhuralevet al. $\left(\mathrm{D}_{6}\right)$

Linear Growth $\left(\mathrm{CG}_{1}\right)$

Cylindrical $\left(\mathrm{CG}_{2}\right)$

Spherical $\left(\mathrm{CG}_{3}\right)$

First- order Chemical Reaction $\left(\mathrm{R}_{1}\right)$

One\&Half - order Chemical Reaction $\left(\mathrm{R}_{2}\right)$

Second -order Chemical Reaction $\left(\mathrm{R}_{3}\right)$

Abbreviations such as D, CG, R etc. in the above kinetic equations refer to the kinetic mechanisms that follow diffusion, contracting geometry and chemical reaction controlled, respectively [28].

\section{RESULTS AND DISCUSSIONS}

\section{Chemical Analysis of the Reduced Samples}

The degree of metallisation of the reduced sinters has been evaluated by standard titrimetric method (IS 15774 : 2007) to understand the influence of time at constant temperature during experiments and tabulated in Table 3 . The degree of metallisation is delineated by the following equation-

$$
\text { Degree of Metallisation }=\frac{F_{\text {Metalle }}}{F e_{\text {Total }}} * 100 \%
$$

Where, $\mathrm{Fe}_{\text {Metallic }}$ is the weight of metallic Fe in the reduced sinters, which are measured by chemical analysis and $\mathrm{Fe}_{\text {Total }}$ is the total weight of Fe present in unreduced sinter (measured by WDXRF analysis).

From Table 3, it has been observed that at 1373K, the degree of metallisation is very low 3.349\% for 5 minutes of reduction time and for 90 minutes the metallisation becomes maximum $50.375 \%$.

Table 3: Degree of Metallisation for Reduced Sinter with Times at 1373K

\begin{tabular}{|l|c|c|c|c|c|c|c|}
\hline Time (min) & $\mathbf{5}$ & $\mathbf{1 0}$ & $\mathbf{1 5}$ & $\mathbf{3 0}$ & $\mathbf{4 5}$ & $\mathbf{6 0}$ & $\mathbf{9 0}$ \\
\hline Degree of Metallisation (\%) & 3.349 & 3.349 & 15.668 & 27.195 & 42.324 & 46.891 & 50.375 \\
\hline
\end{tabular}




\section{Isothermal Kinetic Study of Reduction}

Using data from Table 3, fractional metallisation has been plotted as a function of time at 1373K (Ref. Figure 2).

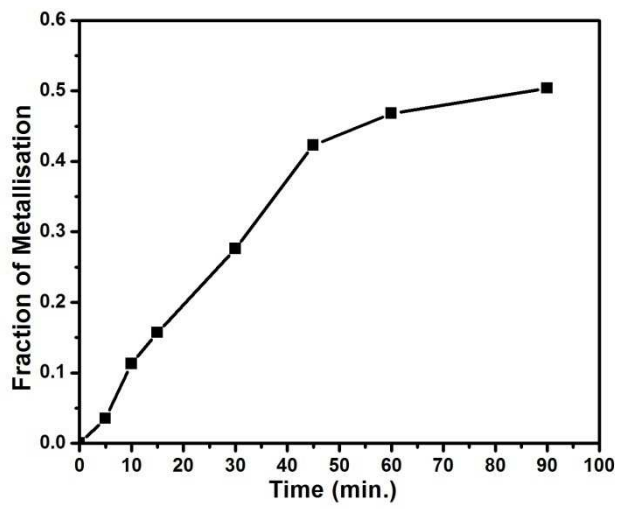

Figure 2: Fraction of Metallisation Vs Time (min) for Reduced Sinter at 1373K

For the determination of exact kinetic mechanism, the reduced time plot has been used. The reduced time plots are shown in Figure 3. From Figure 3, it is found that the experimental $(\alpha, \theta)$ points coincide very well with the theoretical curve for CG3 but after 60 minutes a slight deviation from the theoretical CG3 to D1 curve has been observed for isothermal temperature of $1373 \mathrm{~K}$. Figure 4 shows the plots of $\left[1-(1-\alpha)^{1 / 3}\right]$ for CG3 mechanism as a function of time at constant temperature. The Regression co-efficient $\left(\mathrm{R}^{2}\right)$ value is very close to 1 , showing that the linear fit is very good which also justifies the CG3 mechanism. Therefore, for an initial period of reduction mainly CG3 mechanism is operative. In the initial period the reduction starts from the surface of the granular ore, as a result the metallic surface layer grows and consequently granular ore shrinks. This justifies the mechanism of contracting geometry (CG3). However, as the reduction continues, in the later period the reductant diffuses through the metallic layer to the ore/metal interface and reduction of ore takes place. It is therefore expected that in the later part of reduction the mechanism would be controlled by diffusion. In fact, this is what is tending to be observed in this case (Fig 3).

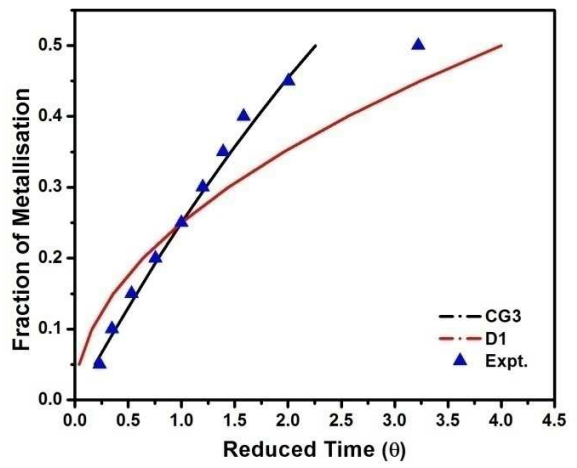

Figure 3: Reduced Time plot of Fraction of Metallisation Along with the Theoretical $\alpha$ Vs $\theta$ Plot for CG3 and D21 at 1323K 


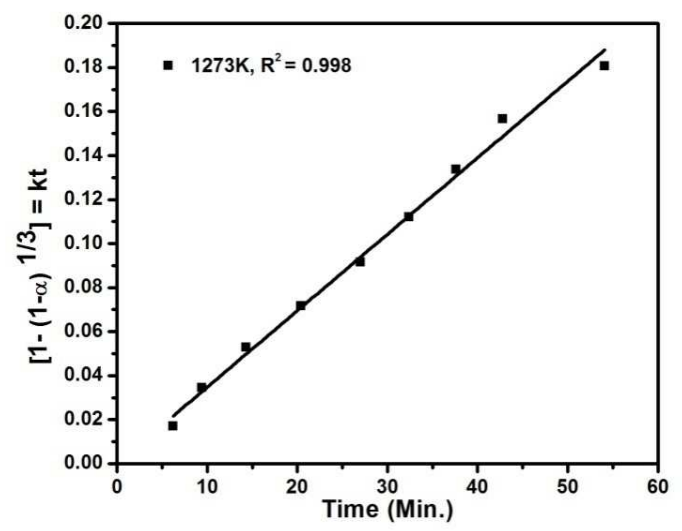

Figure 4: Plots of $\left[1-(1-\alpha)^{1 / 3}\right]$ vs. Time for CG3 for at $1373 K$

Phase Transformation During Reduction

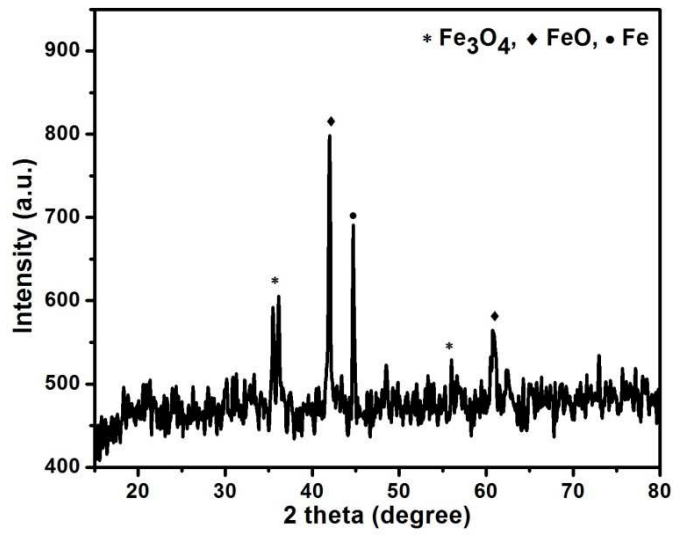

Figure 5: XRD Patterns of Reduced Briquettes at 1373K for 90 Minutes

Figure 5 depicts the XRD analysis of reduced sinter at temperature $1173 \mathrm{~K}$ over 90 minutes of reduction time. Wustite $(\mathrm{FeO})$ is observed as the predominant phase followed by significant intensity peaks of Iron (Fe) and magnetite $\left(\mathrm{Fe}_{3} \mathrm{O}_{4}\right)$. From these observations, it is clearly seen that sinter has not been fully reduced at the given reduction time and mainly sticks to the wustite phase.

\section{CONCLUSIONS}

From the study of the isothermal reduction sinter (collected from Rashtriya Ispat Nigam Ltd. (RINL), India) using coke dust as reductant, it is concluded that the mechanism mainly follows contracting geometry model (CG3) at a fixed temperature of $1373 \mathrm{~K}$. But, there is a tendency at elevated reduction time (after 60 minutes) to divert from the contracting geometry model to diffusion model. Maximum 50.375\% of metallisation has been observed for 90 minutes from reduction time at $1373 \mathrm{~K}$.

\section{REFERENCE}

1. J. D. Litster and A. G. Waters, Influence of the Material Properties of \&on Ore Sinter Feed on Granulation Effectiveness, Powder Technol., 55 (1988), 141-151

2. E. Da Costa, J. P. Coheur, B. Vanderheyden and R. Munnix, Slag Formation in the Adhering Layer of Granules and Its Reaction with Nuclei in Iron Ore Sintering, ISIJ Int., 35 (1995), 138-147 
3. D. Debrincat, C. E. Loo and M. F. Hutchens, Effect of Iron Ore Particle Assimilation on Sinter Structure, ISIJ Int., 44 (2004), 1308-1317

4. C. Loo, Changes in heat transfer when sintering porous goethitic iron ores, Trans. Inst. Min. Metall. (Sect. C: Mineral Process. Extr. Metall.), 109 (2000), C11-22

5. Dongmei LIU and Chin Eng LOO, Importance of Melt Generation and Properties in Iron Ore Sintering, ISIJ International, 56 (2016), pp. 527-536

6. E. F. Abo Zeid \& Yong-Tae Kim, Kinetics and Mechanism of Morphology and Oxygen Reduction Reaction at PdCo Electrocatalysts Synthesized on XC72, International Journal of Nanotechnology and Application (IJNA), Volume 3, Issue 4, September - October 2013, pp. 31-38

7. R. P. Bhagat, Reduction of Solid Fuel Consumption in Sintering of Indian Iron Ore, Science of Sintering, 47 (2015) 205-213

8. C. E. Loo and W. Leung, Factors Influencing the Bonding Phase Structure of Iron Ore Sinters, ISIJ International, 43 (2003), pp. 1393-1402.

9. Zhe Wang, David Pinson, Sheng Chew, Brian Joseph Monaghan, Mark Ian Pownceby, Nathan Alan Stewart Webster, Harold Rogers and Guangqing Zhang, Effects of Sintering Materials and Gas Conditions on Formation of Silico-Ferrites of Calcium and Aluminium during Iron Ore Sintering, ISIJ International, 56 (2016), pp. 1138-1147.

10. A. K. Biswas, Principles of Blast Furnace Ironmaking: Theory and Practice, Cootha Publishing House, Brisbane, (1981), 194.

11. P R Dawson, J Ostwald, and K M Hayes, Influence of alumina on development of complex calcium ferrites in iron-ore sinters. Transactions of the Institution of Mining and Metallurgy Section C-Mineral Processing and Extractive Metallurgy, 94 (1985), C71-C78

12. F. Matsuno and T Hirada, Changes in mineral phases during the sintering of $\mathrm{Fe}_{2} \mathrm{O}_{3}-\mathrm{CaO}-\mathrm{SiO} \mathrm{O}_{2}$ system, Trans. Iron Steel Inst. Jpn., 19 (1979), 595-604

13. Nicola V. Y. Scarlett, Mark I. Pownceby, Ian C. Madsen, and Axel N. Christensen, Reaction Sequences in the Formation of Silico-Ferrites of Calcium and Aluminum in Iron Ore Sinter, Metallurgical and Materials Transactions B, 35B (2004), 929936

14. S. N. Ahsan, T. Mukherjee and J. A. Whiteman, Structure of fluxed sinter, Ironmaking Steelmaking, 10 (1983), 54-64

15. Lauren Andrews, Chin Eng Loo and Geoffrey Evans, Fundamental Forces Driving Analogue Sinter Mix Reshaping, ISIJ International, 56 (2016), pp. 1171-1180

16. C. E. Loo and J. Heikkinen, Structural Transformation of Beds during Iron Ore Sintering, ISIJ Int., 52 (2012), 2158-2167

17. H. P. Pimenta and V. Seshadri, Characterisation of structure of iron ore sinter and its behaviour during reduction at low temperatures, Ironmaking \& Steelmaking, 29 (2002), 169-174

18. J. Ostwald, Mineralogy and micro-texture of Australian iron ore sinters, BHP Technical Bulletin, 25 (1981), 13-20

19. Ammar Khawam and Douglas R. Flanagan, Solid-State Kinetic Models: Basics and Mathematical Fundamentals, J. Phys. Chem. B, 110 (2006), 17315-17328.

20. C.F. Dickinson and G.R. Heal, Solid-liquid diffusion controlled rate equations, Thermochimica Acta, 340-341 (1999), 89-103.

21. Z. Jian-liang, X. Xiang-dong, C. Ming-ming, J. Ke-Xin, W. Chun-long and R. Shan, Reduction kinetics of vanadium titanomagnetite carbon composite pellets adding catalysts under high temperature. J. Iron Steel Res. Int. 20 (2013), 01-07. 
22. A. Ghosh, Kinetics of Reduction of Iron Oxide in Mixtures of Oxide and Carbon: A Critical Appraisal, Trans Indian Inst Met., 66(2013), 71-77.

23. Y.M. Wang and Z.F. Yuan, Reductive Kinetics of the Reaction between a Natural Ilmenite and Carbon, International Journal of Mineral Processing, 81 (2006), 133

24. P. Kowitwarangkul, A. Babich, D. Senk, Reduction Kinetics of Self-Reducing Pellets of Iron Ore, AISTech 2014 Proceedings. (C) 2014 by AIST, 611-622.

25. Bitan Kumar Sarkar, Saikat Samanta, Rajib Dey, Gopes Chandra Das, A study on reduction kinetics of titaniferous magnetite ore using lean grade coal, International Journal of Mineral Processing 152 (2016) 36-45

26. R. Sah and S. K. Dutta, Kinetic Studies of Iron Ore-Coal Composite Pellet Reduction by TG-DTA, Trans Indian Inst Met., 64(2011), 583-591.

27. Jae-Cheol Lee, Dong-Joon Min, and Sung-Soo Kim, Reaction Mechanism on the Smelting Reduction of Iron Ore by Solid Carbon, Metallurgical and Materials Transactions B, 28B (1997), pp. 1019-1028. 